insignificant portion of the tumour, and the muscular tissue has no regular arrangement with regard to them. For that reason, I think, the tumour must be termed a myoma rather than an angioma.

( $T o$ be continued.)

\title{
THE DANGERS OF COW'S MILK IMMEDIATELY AFTER PARTURITION.
}

\author{
By Thomas Walley, M.R.C.V.S., Royal Veterinary College, \\ Edinburgh.
}

AMONG the many important subjects dealt with during the meetings of the Hygienic Congress, the use of colostral milk does not hold a high position, but the question is at least somewhat novel, and one that comes within the province of veterinary medicine.

In his paper on "The Regulation of the Milk Supply with reference to Diseases transmissible by Milk," Dr Ostertag of Berlin placed colostral milk in the first group of milks which in his opinion should, for sanitary reasons, be excluded from the market, as, without being necessarily prejudicial to health, it was peculiar in consistence.

In the course of the discussion Dr Henry Armstrong of Newcastleon-Tyne expressed the opinion "that milk containing colostrum has an injurious effect, by acting as a purgative on children, and that it should not be sold."

Now, what are the facts in connection with the consumption of colostral milk? Like many other things, the use of colostral milk from the cow for the purposes of human food is largely regulated by custom.

In all the dairy districts in the Midland Counties of England colostral milk ("beest" or "beestings") is highly prized, and after the calf has had its fill (in cases where the calf is allowed to suck its mother) the surplus milk is withdrawn from the udder, and either sold or given away for the purpose of making custard. It is not, as a rule, added to the general yield of milk, though undoubtedly its addition thereto would be the means of producing an improved quality, so far, at least, as the proportion of fat is concerned. In most of the parts of Scotland with which the writer is acquainted the suggestion that colostral milk should be used would be received with a feeling of disgust, but here again, use and wont step in, just as in the employment of mushrooms as edible material.

It is generally acknowledged by physiologists that colostrum serves a very important and salutary action on the bowels of the young animals, by acting as a mild purgative, and in this way assisting in the evacuation of meconium ; but a much wider question than the possible production of catharsis in children is involved in the use of colostral inilk, viz., the question as to what period should be allowed to elapse after parturition before milk is added to the general yield?

It is well known to all who are conversant with the parturient and post-parturient conditions of the cow that a variety of circumstances may injuriously affect the milk, e.g., retention of the placenta or of blood clots in the uterus ; metritis-septic or non-septic ; the discharge' 
of lochia, and the advent of the cestral period; and these conditions are of far greater importance in the case of single cows than in the case of large numbers, in which any deleterious matter is largely rendered inert by dilution. I am informed by Professor M'Fadyean that one of the rules insisted upon by the Milk Supply Association of Copenhagen is, that milk from newly calved cows shall not be used until a period of twelve days has elapsed. Whether such a regulation is in all cases necessary may be an open question. Certainly if such a regulation were attempted to be enforced in connection with dairies in this country, it would be more frequently honoured in the breach than in the observance, as most dairymen are anxious to obtain the use of their new purchases within as short a period as possible after parturition. Perhaps we, in this country, are not so strict in reference to our milk supply as we ought to be, and we certainly have not attained the high ideal of dairy women in certain Continental districts, in which no menstruating woman ever dreams of engaging in dairying operations.

During the course of the discussion on Dr Ostertag's paper Dr Armstrong stated that in his opinion milk from animals affected with tuberculosis or parturient fever should not be sold; he said, in effect, that these two maladies should be added to the list of scheduled diseases.

In the minds of not a few of those present during the discussion this statement of Dr Armstrong's aroused some feeling of astonishment; and this feeling was not allayed until, in answer to a question by the writer, Dr Armstrong explained that what he meant by parturient fever was the condition known as puerperal fever in the human subject. In his further explanatory remarks Dr Armstrong complained, and justly so too, that the differentiation of parturient maladies in the cow by veterinary surgeons was extremely vague and unsatisfactory. With this complaint most of those who have studied the question will concur. It is sometimes very painful to observe in the discussions on the subject which take place at veterinary meetings the hopeless muddle into which many veterinary surgeons launch themselves in attempting to differentiate parturient and post-parturient maladies in the cow.

In 1874 the writer attempted to introduce a reasonable classification of parturient affections in a paper read by him at a meeting of the Scottish Metropolitan Veterinary Medical Association; and still more recently he has urged the advisability of the adoption of some rational classification. Much of the mystification which has arisen in connection with this question is undoubtedly due to the various views (often the result of ignorance, or imperfect observation) entertained by different authorities as to the nature and pathology of parturient maladies. Thus, we find one authority asserting that milk fever in the cow is identical with the puerperal eclampsia of woman, another that it is the analogue of puerperal fever, another that it is due to an anæmic condition of the cerebral circulation, while another holds that it is an apoplectic lesion, and still another that it is congestive in its nature. If we could arrive at some sensible and scientific differentiation of these maladies, it would not only lead to the adoption of a more scientific method of treatment in each case, but it would also be the means of removing the hazy notions at present entertained by 
many veterinary practitioners as to the nature of the parturient affections with which they have to deal.

Without wishing to be dictatorial, the writer would suggest that some such classification of these maladies as the following should be adopted.

(r.) Parturient Fever.-A febrile condition, usually transient, and of a benign character ; the result of reaction after exhaustion or chill, or produced by traumatism or the retention of clots of blood in the uterus.

(2.) Parturient Convulsions (Eclampsia). - In which clonic (and occasionally tonic) spasm of the voluntary muscles occurs, with more or less delirium and temporary loss of volition and of motion; arising as the result of some reflex uterine, gastric, or intestinal, influence, e.g., uterine spasm, gastric, or intestinal, or gastro-intestinal derangement; and in which there is undoubtedly established cerebral anæmia.

(3.) Cerebral (Parturient) Apoplexy in which there is actual rupture of the cerebral vessels, with extravasation of blood, and, as a result, clonic spasms and delirium followed by coma, or immediate coma unassociated with such conditions.

(4.) Cerebro-Spinal (Parturient) Congestion in which the onset of the disease is gradual, and in which the commencement of the lesion is confined to the posterior part of the spine, gradually involving its whole length and ultimately the brain-the prominent symptoms being paralysis (more or less pronounced) of the hind quarters, gradually extending forward and terminating in complete paralysis with coma.

(5.) Septic Metritis-the puerperal fever of many obstetricians-in which, owing to the retention and decomposition of blood clots, particles of placentr, or, it may be, portions of a decomposing foetus, septic processes are set up, and induce (by absorption) septic intoxication or septic infection.

\section{EDITORIAL ARTICLES. \\ THE CAUSE OF EQUINE INFLUENZA.}

IT is not yet twenty years since glanders was by many veterinary surgeons, both in this country and on the Continent, regarded as a disease which occasionally made its appearance spontaneouslythat is to say, apart altogether from direct or indirect contact with a previous case of the disease. The affection was ascribed to "the introduction into the blood of vitiated or decomposing material generated in the external surroundings of the animal," or to "the formation of degenerated material within the animal system." Years before the discovery of the glanders bacillus, enlightened observers had contested this view of the etiology of glanders, and maintained that the disease had but one cause-the transference of a contagium from 